\title{
The role of human papillomavirus genotyping for detecting high-grade intraepithelial neoplasia or cancer in HPV- positive women with normal cytology: a study from a hospital in northeastern China
}

\author{
Jing Zhang ${ }^{1 \dagger}$, Deyu Zhang ${ }^{2 \dagger}$, Zhuo Yang ${ }^{1}$, Xiaobin Wang ${ }^{1}$ and Danbo Wang ${ }^{1 *}$ (D)
}

\begin{abstract}
Background: Human papillomavirus (HPV) testing is more sensitive than cytology for detecting cervical cancer and its precursors. This study aimed to analyze the prevalence of high-risk HPV genotypes and evaluate the role of HPV genotyping triage for detecting high-grade squamous intraepithelial lesions, adenocarcinoma in situ and cervical cancer (HSIL+) in HPV-positive women with normal cytology.
\end{abstract}

Methods: A retrospective study was performed in women who had undergone co-screening at the China Medical University-affiliated Shengjing Hospital between 2012 and 2014.

Results: Of the 34,587 women, 2665 HPV-positive women with normal cytology who had received colposcopy were eligible for analysis. In HSIL+ groups of 204 women, the common genotypes were HPV16, HPV52, HPV58, HPV33, HPV31 and HPV18 in order of prevalence. The proportion of histological HSIL+ in women infected with HPV33 or HPV31 was not significantly different compared to women infected with HPV16 $(P=0.30, P=0.19$, respectively). The odds ratios for histological HSIL+ were 3.26 (95\% confidence interval [CI]: $2.41-4.40$ ) in women with HPV16/18, 4.21 (95\% Cl: 2.99-5.93) in those with HPV16/18/31/33, and 5.73 (95\% Cl: 3.30-9.97) in those with HPV16/18/31/33/52/58. Including HPV31/33 genotyping together with HPV16/18 significantly increased the proportion of HSIL+ detection from 63.2 to $77.5 \%(P=0.002)$ without significantly increasing the colposcopy per HSIL+ detection ratio (7.7 to $8.1, P=0.66)$.

Conclusions: HPV genotyping played an important role in managing HPV-positive women with normal cytology. Genotyping for HPV31/33 should be added to the previously recommended HPV16/18 genotyping in triaging HPVpositive women in northeastern China.

Keywords: Human papillomavirus, hrHPV prevalence, HPV genotyping, High-grade squamous intraepithelial lesion, Cervical cancer

\footnotetext{
* Correspondence: wangdanbo@cancerhosp-In-cmu.com

† Jing Zhang and Deyu Zhang contributed equally in this work and should be considered as first co-authors.

'Department of Gynecology, Cancer Hospital of China Medical University, Liaoning Cancer Hospital and Institute, No.44 Xiaoheyan Road, Shenyang 110042, Liaoning province, China

Full list of author information is available at the end of the article
}

(c) The Author(s). 2020 Open Access This article is licensed under a Creative Commons Attribution 4.0 International License, which permits use, sharing, adaptation, distribution and reproduction in any medium or format, as long as you give appropriate credit to the original author(s) and the source, provide a link to the Creative Commons licence, and indicate if changes were made. The images or other third party material in this article are included in the article's Creative Commons licence, unless indicated otherwise in a credit line to the material. If material is not included in the article's Creative Commons licence and your intended use is not permitted by statutory regulation or exceeds the permitted use, you will need to obtain permission directly from the copyright holder. To view a copy of this licence, visit http://creativecommons.org/licenses/by/4.0/. The Creative Commons Public Domain Dedication waiver (http://creativecommons.org/publicdomain/zero/1.0/) applies to the data made available in this article, unless otherwise stated in a credit line to the data. 


\section{Background}

Cervical cancer is the fourth most common cancer among women worldwide and the leading cause of death from cancer in developing countries [1]. Approximately 40 human papillomavirus (HPV) genotypes are associated with infection of the lower genital tract [2]. HPVs are classified as high- or low-risk according to their oncogenic potential [3]. Persistent infection of high-risk HPV (hrHPV) is necessary for developing cervical cancer and its precursors [4].

Recently, HPV genotyping has been accepted in preference to cytology for detecting cervical cancer and its precursors, due to its higher sensitivity [5]. Based on guidelines published in 2012 by the American Cancer Society (ACS), the American Society for Colposcopy and Cervical Pathology (ASCCP), and the American Society for Clinical Pathology (ASCP), a combination of cervical cytology and HPV testing (co-screening) is the preferred screening method for women aged 30-65 years old. It is recommended that HPV16/18-positive women with normal cytology should be referred for immediate colposcopy, whereas those testing positive for other hrHPV genotypes should be followed up in 1- year [6]. In April 2014, the American Food and Drug Administration (FDA) approved cobas $^{\circledast} 4800 \mathrm{HPV}$ testing as an option for primary screening, which provides genotyping information for HPV16/18, while simultaneously reporting the 12 other hrHPV types; therefore, women with potential positivity for the 12 other possible hrHPV genotypes are triaged by cytology [5]. Thus, whether adopting coscreening or HPV primary screening, there would be a proportion of HPV-positive women with normal cytology. On one hand, HPV testing has a low specificity and a low positive predictive value, which may increase colposcopy burden and overtreatment [7]. On the other hand, genotyping solely for HPV16/18 would miss a proportion of patients with high-grade cervical lesions, since mounting evidence suggests that the risk of high-grade squamous intraepithelial lesions, adenocarcinoma in situ and cervical cancer (HSIL+) in women positive for HPV31, 33, 52 and 58 is equivalent to or greater than that in women positive for HPV18 [8-10]. Therefore, managing hrHPV positive women with normal cytology is a major issue. Furthermore, HPV genotype prevalence and vaccination rates are diverse among regions. A meta-analysis reported that the most common HPV types detected in invasive cervical cancer (ICC) cases from Eastern Asia were HPV16, 18, 58, 52, 33, 31, 45 and 59 [11]. Another study showed that in cervical intraepithelial neoplasia (CIN) $2 / 3$ and adenocarcinoma in situ samples, HPV 16, 52, 58, 51, 33, 31, 18 and 35 were the most common HPV types in five Asian countries [12]. The data collected from other countries may not, therefore, represent the situation in China $[13,14]$.
Introducing HPV testing for cervical cancer screening is becoming increasingly popular in China. Coscreening, HPV primary screening or cytology primary screening has been used in different districts of China due to unbalanced economic development. It is uncertain which combinations of hrHPV genotyping could provide the optimal triage of HPV-positive women with normal cytology in clinical practice in northeastern China. To address these concerns, a retrospective study was conducted to evaluate the prevalence of HPV, and the association between hrHPV genotypes and the detection of histological HSIL+ in northeastern China. Furthermore, an acceptable triage strategy to reduce the burden of cytological examination and increase the proportion of detecting histological HSIL+ was investigated.

\section{Methods}

\section{Study population}

We recruited women between 25 and 65 years old who underwent co-screening for cervical cancer when visiting outpatient of the Department of Obstetrics and Gynecology at the China Medical University-affiliated Shengjing Hospital between January 1st 2012 and December 31st 2014. The clinical characteristics and pathological data were obtained from the hospital's electronic files, including age at diagnosis, cytology results, HPV genotyping results, colposcopy results and histological results. Exclusion criteria for the present study were pregnant women; women who had a hysterectomy; women with a history of cervical cancer; and women who had received previous treatment for any cervical epithelial lesion. The study was approved by the ethics committee of Liaoning Cancer Hospital and Institute (20190971).

\section{Cytology}

Cytological testing was performed using ThinPrep ${ }^{\circledR}$ liquid-based cytology (Hologic Inc., MA, USA). Cell samples were collected using a cytobrush and placed into a tube with transport medium. The first sample from each woman was used for cytology analysis. The second sample was taken for HPV genotyping testing. Slides were screened by two cytotechnologists and diagnosed according to the 2001 Bethesda system.

\section{HPV genotyping}

HPV genotyping was identified by the HPV GenoArray test kit (Hybribio Ltd., Hong Kong). This assay was performed using both DNA amplification by the L1 consensus primer-based polymerase chain reaction (PCR) and a flow-through hybridization technique. A total of 21 genotypes were screened, including13 high-risk genotypes (HPV16, HPV18, HPV31, HPV33, HPV35, HPV39, HPV45, HPV51, HPV52, HPV56, HPV58, HPV59 and 
HPV68), two probable high-risk genotypes (HPV53 and HPV66) and six low-risk genotypes (HPV6, HPV11, HPV42, HPV43, HPV44 and CP8304) [15]. Positive and negative control samples were included in each experiment.

\section{Colposcopy and biopsy}

All women with abnormal cytology or those who tested positive for HPV were referred for colposcopy. A colposcopy-guided biopsy was performed if a suspicious lesion was found. Random cervical biopsy was carried out when colposcopic inspection was inadequate. If colposcopy results were normal upon adequate inspection, women were followed up yearly without biopsy. The grade of the cervical lesion was independently diagnosed by two expert pathologists, according to the 4th edition of the WHO Women's Reproductive System Tumor Classification [16]. Histological high-grade squamous intraepithelial lesion (HSIL) included CIN2, CIN3 and squamocarcinoma in situ. The suffix " + " meant the indicated or more severe histology. HSIL, adenocarcinoma in situ and cervical cancer were designated as HSIL+ in the present study. Immunohistochemical stains for p16 and Ki67 were used when a consensus was not reached.

\section{Data analysis}

The prevalence of HPV was expressed as a proportion of the number of HPV-positive cases compared to the total number of cases tested for HPV. Multiple HPV infections were defined as those positive for two or more types of HPV. Women with multiple HPV infections were counted more than once for each positive genotype. The prevalence of specific HPV types is presented for the $13 \mathrm{hrHPV}$ types and two probable hrHPV types in women with hrHPV infection, as well as hrHPV positive women with normal cytology and histological HSIL+ women who received colposcopy with hrHPV positivity and normal cytology. Chi-squared $\left(x^{2}\right)$ tests were used to compare differences of the proportions of histological HSIL+ in hrHPV positive women with normal cytology who received colposcopy, across all four age groups, and among hrHPV genotypes, as well as between each pairing of two genotypes. Logistic regression analysis, which was adjusted for age, was used to estimate the association between specific hrHPV genotypes and the proportion of detecting histological HSIL+. Odds ratios (ORs) with 95\% confidence intervals (CIs) were calculated. Data were analyzed using the SPSS version 22.0 software (SPSS Inc., Chicago, IL, USA). A $P$ value of $<0.05$ was considered statistically significant.

\section{Results}

Characteristics of the study population

A total of 34,587 women aged 25-65 years old attended our hospital for cervical cancer co-screening; 4198 of these women (12.1\%) had hrHPV infection and 1839 (5.3\%) had abnormal cytology results (Fig. 1). Multiple HPV infections were detected in 676 of the 4198 (16.1\%) infected women. The most common hrHPV genotype was HPV16 (1373, 32.7\%), followed by HPV58 (680, 16.2\%), HPV52 (571, 13.6\%), HPV53 (504, 12.0\%), HPV33 (360, 8.6\%) and HPV18 (301, 7.2\%).

\section{hrHPV positive women with normal cytology}

Of the $4198 \mathrm{hrHPV}$ infected women, 2897 (69.0\%) women with normal cytology were analyzed in the present study. The mean age of these women was $39.60 \pm 8.99$ years old, with a median age of 40 . The top six hrHPV genotypes were HPV16 (874, 30.2\%), HPV58 (452, 15.6\%), HPV52 (395, 13.6\%), HPV53 (380, 13.1\%), HPV18 (224, 7.7\%) and HPV33 (208, 7.2\%). Regarding each hrHPV genotype, the proportion of women with normal cytology was higher in those infected with HPV59 (76.3\%), HPV45 (75.8\%), HPV53 (75.4\%), HPV18 (74.4\%) and HPV51 (70.65\%) than other hrHPV genotypes (Table 1).

\section{hrHPV genotype and HSIL+ incidence}

Colposcopy was performed in 2665 HPV-positive women with normal cytology. Colposcopy-guided biopsy and random biopsy were carried out in $1742(1742 / 2665$, $65.4 \%)$ women. A total of 204 women $(204 / 2665,7.7 \%)$ had HSIL+; 173 women $(173 / 2665,6.5 \%)$ had low-grade squamous intraepithelial lesions; and 2288 women $(2288 / 2665,85.8 \%)$ had negative histology results or normal colposcopy results. Of the 204 women with HSIL+, 26 women $(26 / 204,12.7 \%)$ had ICC (24 cases with squamous cervical cancer and two cases with adenocarcinoma), including 14 women $(14 / 26,53.8 \%)$ who were FIGO stage IA. In the HSIL+ group, the prevalence of the hrHPV genotypes was HPV16 (119, 58.3\%), HPV52 (28, 13.7\%), HPV58 (26, 12.7\%), HPV33 (22, 10.8\%), HPV31(15, 7.4\%) and HPV18 (12, 5.9\%). The percentage of women infected with multiple hrHPV genotypes was $19.1 \%(39 / 204)$ in the HSIL+ group. In the squamous cervical cancer group, the prevalence of HPV16 (18/24, $75 \%)$ was prominent. Of the seven cases of adenocarcinoma in situ and adenocarcinoma, five cases were HPV18-positive and two cases were HPV16-positive, including one case of dual infection with HPV18 and HPV33 (Table 1).

\section{hrHPV genotypes and detection of histological HSIL+} The proportion of histological HSIL+ in hrHPV positive women with normal cytology who received colposcopy 


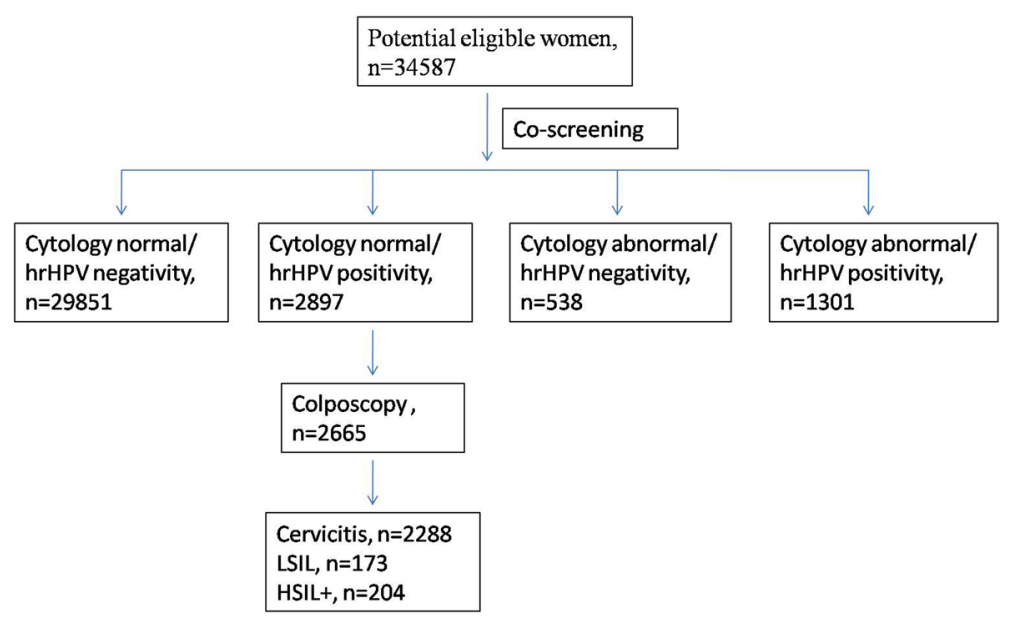

Fig. 1 Flowchart for the study population. (hrHPV, high risk human papillomavirus; HSIL+, histologic high-grade squamous intraepithelial lesions, adenocarcinoma in situ and cervical cancer)

did not differ significantly by age group (divided into $25-34,35-44,45-54$ and $55-65$ years old. $P=0.42$ ). Of the 801 HPV16-positive women with normal cytology who received colposcopy, 119 (119/801, 14.9\%) women were confirmed as HSIL+ by histological diagnosis. The proportion of histological HSIL+ in each genotype was greater than $10 \%$ for HPV16 (14.9\%), HPV33 (22/187, $11.8 \%)$ and HPV31 (15/142, 10.6\%). The proportion of histological HSIL+ in each genotype was less than 10\% for HPV52 (28/362, 7.7\%), HPV58 (26/414, 6.3\%), HPV18 (12/206, 5.8\%) and other types. Compared to women infected with HPV16, the proportion of histological HSIL+ was not significantly different in women infected with HPV33 or HPV31 $(P=0.30, P=0.19$, respectively). While HPV58, HPV52, HPV53 and HPV18 were four of the top six most common genotypes in

Table 1 The prevalence of hrHPV genotypes in 2897 hrHPV positive women with normal cytology

\begin{tabular}{|c|c|c|c|c|c|c|c|}
\hline $\begin{array}{l}\text { hrHPV } \\
\text { genotypes }\end{array}$ & $\begin{array}{l}\text { Total, } n= \\
4198,(\%)\end{array}$ & $\begin{array}{l}\text { No. of hrHPV positive } \\
\text { women with normal } \\
\text { cytology } n=2897 \text {, } \\
\text { (\%) }\end{array}$ & $\begin{array}{l}\text { The percentages of } \\
\text { women with normal } \\
\text { cytology in hrHPV } \\
\text { positive women (\%) }\end{array}$ & $\begin{array}{l}\text { No. of } \\
\text { histological } \\
\text { HSIL+, } n= \\
204,(\%)\end{array}$ & $\begin{array}{l}\text { No. of } \\
\text { histological } \\
\text { high-grade } \\
\text { squamous } \\
\text { intraepithelial } \\
\text { lesion, } n= \\
173,(\%)\end{array}$ & $\begin{array}{l}\text { No. of histological } \\
\text { adenocarcinoma in situ } \\
\text { and adenocarcinoma, } \\
n=7,(\%)\end{array}$ & $\begin{array}{l}\text { No. of histological } \\
\text { squamous } \\
\text { cervical cancer, } \\
n=24,(\%)\end{array}$ \\
\hline 16 & $1373(32.7)$ & $874(30.2)$ & 63.7 & 119(58.3) & $99(57.2)$ & $2(28.6)$ & 18(75.0) \\
\hline 18 & $301(7.2)$ & $224(7.7)$ & 74.4 & $12(5.9)$ & $6(3.5)$ & $5(71.4)$ & $1(4.2)$ \\
\hline 31 & $221(5.3)$ & 154(5.3) & 69.7 & $15(7.4)$ & $13(7.5)$ & 0 & $2(8.3)$ \\
\hline 33 & $360(8.6)$ & $208(7.2)$ & 57.8 & $22(10.8)$ & $21(12.1)$ & $1(14.3)$ & 0 \\
\hline 35 & $41(1.0)$ & $22(0.8)$ & 53.7 & 0 & 0 & 0 & 0 \\
\hline 39 & 234(5.6) & $169(5.8)$ & 72.2 & $5(2.5)$ & $5(2.9)$ & 0 & 0 \\
\hline 45 & $62(1.5)$ & $47(1.6)$ & 75.8 & $2(0.1)$ & $2(1.1)$ & 0 & 0 \\
\hline 51 & $143(3.4)$ & $101(3.5)$ & 70.6 & $4(2.0)$ & $3(1.7)$ & 0 & $1(4.2)$ \\
\hline 52 & $571(13.6)$ & 395(13.6) & 69.2 & $28(13.7)$ & $28(16.2)$ & 0 & $0(0)$ \\
\hline 53 & $504(12.0)$ & $380(13.1)$ & 75.4 & $10(4.9)$ & $9(5.2)$ & 0 & $1(4.2)$ \\
\hline 56 & $75(1.8)$ & $37(1.3)$ & 49.3 & 0 & 0 & 0 & 0 \\
\hline 58 & $680(16.2)$ & $452(15.6)$ & 66.5 & $26(12.7)$ & $25(14.5)$ & 0 & $1(4.2)$ \\
\hline 59 & $93(2.2)$ & $71(2.5)$ & 76.3 & $1(0.05)$ & 0 & 0 & $1(4.2)$ \\
\hline 66 & 209(5.0) & 143(4.9) & 68.4 & $7(3.4)$ & $7(4.0)$ & 0 & 0 \\
\hline 68 & $166(4.0)$ & $115(4.0)$ & 69.3 & $4(2.0)$ & $4(2.3)$ & 0 & 0 \\
\hline
\end{tabular}

Women with multiple HPV types detected are counted to each type, and therefore counted more than once 
HPV-positive women with normal cytology, the proportion of histological HSIL+ in each of these four HPV genotypes was significantly lower than those in women infected with HPV16 $(P<0.001, P=0.001, P<0.001$ and $P<0.001$, respectively). The proportion of histological HSIL+ in women infected with HPV33 was significantly higher compared to those infected with HPV18 or HPV58 ( $P=0.047, P=0.03$, respectively). The differences between the proportion of histological HSIL+ in women infected with HPV18 and those infected with the HPV31, HPV52 or HPV58 were not statistically significant $(P=0.15, P=0.50, P=1.00$, respectively) (Table 2$)$. The proportion of histological HSIL+ in women infected with multiple genotypes was significantly higher than those with a single infection $(P=0.03)$ (Table 2).

Among all 2665 women with hrHPV-positive and cytology-negative results, following adjustment for age, the odds ratio (OR) for histological HSIL+ was 3.75 (95\% CI $=2.79-5.05)$ in women with HPV16 infection, compared to women with non-HPV16 infection. In women infected with HPV33, the OR for histological HSIL+ was 1.69 (95\% CI $=1.04-2.72)$. Infection with HPV genotypes $18,31,52$ or 58 did not increase the risk of HSIL+ $(\mathrm{OR}=0.72,1.46,1.03,0.78,95 \% \mathrm{CI}=0.39$ $1.32,0.83-2.57,0.68-1.57,0.51-1.20$, respectively). The OR for histological HSIL+ was $3.26(95 \% \mathrm{CI}=2.41-4.40)$ in women with HPV16/18 infection. The OR for histological HSIL+ was $4.21(95 \% \mathrm{CI}=2.99-5.93)$ in women infected with HPV16/18/31/33. The OR for histological HSIL+ was $5.73(95 \% \mathrm{CI}=3.30-9.97)$ in women infected with HPV16/18/31/33/52/58 (Table 3).

HPV16/18 infection was detected in 129 of 204 (63.2\%) women with histological HSIL+; by contrast, the top six hrHPV genotypes (HPV16/18/31/33/52/58) in the HSIL+ group were detected in 190 (190/204, 93.1\%) women. However, the colposcopy per HSIL+ detection ratio also increased significantly from 7.7 to $10.2(P=$ 0.01 ). Adding the HPV31/33 genotype to the HPV16/18 genotype increased the percentage of HSIL+ detection from 63.2 to $77.5 \%(P=0.002)$ without significantly increasing the colposcopy per HSIL+ detection ratio (7.7 to $8.1, P=0.66)$. (Table 3 ).

\section{Discussion}

Cervical cancer screening has regional differences in China. In relatively developed areas of China, co-

Table 2 Comparison of the proportions of HSIL+ among different age groups and hrHPV genotypes in hrHPV positive women with normal cytology who received colposcopy

\begin{tabular}{|c|c|c|c|c|c|c|c|c|}
\hline & & $\begin{array}{l}\text { No. of hrHPV positive women with normal cytology who } \\
\text { received colposcopy, } n=2665\end{array}$ & $\begin{array}{l}\text { No. of } \\
\text { histological } \\
\text { HSIL+ }\end{array}$ & $\begin{array}{l}\text { Percentages } \\
\text { of HSIL+ }\end{array}$ & $\begin{array}{l}x^{2} \\
\text { value }\end{array}$ & $P$ value & & \\
\hline \multirow{4}{*}{$\begin{array}{l}\text { Age } \\
\text { groups }\end{array}$} & $25-34$ & 923 & 61 & 6.6 & \multirow[t]{4}{*}{2.81} & \multirow[t]{4}{*}{0.42} & & \\
\hline & $35-44$ & 975 & 84 & 8.6 & & & & \\
\hline & $45-54$ & 585 & 46 & 7.9 & & & & \\
\hline & $55-65$ & 182 & 13 & 7.1 & & & & \\
\hline \multirow{2}{*}{$\begin{array}{l}\text { HPV } \\
\text { infection }\end{array}$} & single & 2296 & 165 & 7.2 & \multirow[t]{2}{*}{5.15} & \multirow[t]{2}{*}{0.03} & & \\
\hline & multiple & 369 & 39 & 10.6 & & & & \\
\hline \multirow{15}{*}{$\begin{array}{l}\text { hrHPV } \\
\text { genotype }\end{array}$} & 16 & 801 & 119 & 14.9 & \multirow[t]{15}{*}{$82.37^{*}$} & $<0.001^{*}$ & & \\
\hline & 18 & 206 & 12 & 5.8 & & $<0.001^{\mathrm{a}}$ & & \\
\hline & 31 & 142 & 15 & 10.6 & & $0.19^{a}$ & $0.15^{b}$ & \multirow[t]{6}{*}{$0.86^{\mathrm{C}}$} \\
\hline & 33 & 187 & 22 & 11.8 & & \multirow[t]{5}{*}{$0.30^{\mathrm{a}}$} & \multirow[t]{5}{*}{$0.047^{b}$} & \\
\hline & 35 & 21 & 0 & 0 & & & & \\
\hline & 39 & 155 & 5 & 3.2 & & & & \\
\hline & 45 & 43 & 2 & 4.7 & & & & \\
\hline & 51 & 93 & 4 & 4.3 & & & & \\
\hline & 52 & 362 & 28 & 7.7 & & $0.001^{a}$ & $0.50^{b}$ & $0.19^{c}$ \\
\hline & 53 & 349 & 10 & 2.9 & & \multirow[t]{2}{*}{$<0.001^{\mathrm{a}}$} & & \\
\hline & 56 & 34 & 0 & 0 & & & & \\
\hline & 58 & 414 & 26 & 6.3 & & \multirow[t]{4}{*}{$<0.001^{\mathrm{a}}$} & \multirow[t]{4}{*}{$1.00^{\mathrm{b}}$} & \multirow[t]{4}{*}{$0.03^{c}$} \\
\hline & 59 & 65 & 1 & 1.5 & & & & \\
\hline & 66 & 131 & 7 & 5.3 & & & & \\
\hline & 68 & 105 & 4 & 3.8 & & & & \\
\hline
\end{tabular}


Table 3 Detection of histologic high-grade squamous intraepithelial lesion or worse lesions by different hrHPV genotyping approaches in the study population

\begin{tabular}{|c|c|c|c|c|c|c|c|}
\hline & $\begin{array}{l}\text { No. of hrHPV positive women with normal cytology } \\
\text { and with availble histologic or colposcopic results }\end{array}$ & $\begin{array}{l}\text { No. of } \\
\text { histologic } \\
\text { HSIL+ }\end{array}$ & $\begin{array}{l}\text { Percentage of HSIL+ } \\
\text { detected, } n=204\end{array}$ & $\begin{array}{l}\text { Ratio of colposcopy } \\
\text { per HSIL+ detection }\end{array}$ & OR & $\begin{array}{l}95 \% \\
\mathrm{Cl}\end{array}$ & $\begin{array}{l}P \\
\text { value }\end{array}$ \\
\hline HPV16 & 801 & 119 & 58.3 & 6.7 & 3.75 & $\begin{array}{l}2.79- \\
5.05\end{array}$ & $\begin{array}{l}< \\
0.001\end{array}$ \\
\hline HPV18 & 206 & 12 & 5.9 & 17.2 & 0.72 & $\begin{array}{l}0.39- \\
1.32\end{array}$ & 0.29 \\
\hline HPV31 & 142 & 15 & 7.4 & 9.5 & 1.46 & $\begin{array}{l}0.83- \\
2.57\end{array}$ & 0.19 \\
\hline HPV33 & 187 & 22 & 10.8 & 8.5 & 1.69 & $\begin{array}{l}1.04- \\
2.72\end{array}$ & 0.03 \\
\hline HPV52 & 362 & 28 & 13.7 & 12.9 & 1.03 & $\begin{array}{l}0.68- \\
1.57\end{array}$ & 0.90 \\
\hline HPV58 & 414 & 26 & 12.7 & 15.9 & 0.78 & $\begin{array}{l}0.51- \\
1.20\end{array}$ & 0.26 \\
\hline HPV16/18 & 992 & 129 & 63.2 & 7.7 & 3.26 & $\begin{array}{l}2.41- \\
4.40\end{array}$ & $\begin{array}{l}< \\
0.001\end{array}$ \\
\hline $\begin{array}{l}\text { HPV16/18/ } \\
33\end{array}$ & 1162 & 148 & 72.5 & 7.9 & 3.85 & $\begin{array}{l}2.79- \\
5.31\end{array}$ & $\begin{array}{l}< \\
0.001\end{array}$ \\
\hline $\begin{array}{l}\text { HPV16/18/ } \\
31 / 33\end{array}$ & 1282 & 158 & 77.5 & 8.1 & 4.21 & $\begin{array}{l}2.99- \\
5.93\end{array}$ & $\begin{array}{l}< \\
0.001\end{array}$ \\
\hline $\begin{array}{l}\text { HPV16/18/ } \\
31 / 33 / 52 / 58\end{array}$ & 1938 & 190 & 93.1 & 10.2 & 5.73 & $\begin{array}{l}3.30- \\
9.97\end{array}$ & $\begin{array}{l}< \\
0.001\end{array}$ \\
\hline
\end{tabular}

screening is commonly performed in hospitals [10], and it is clear that women with abnormal cytology and hrHPV positivity should be referred for colposcopy [17]; however, the management of hrHPV positive women with normal cytology remains controversial. The triage of HPV primary screening faces the same problem. Several studies have shown that the current cervical screening strategy with HPV16/18 genotyping misses some non-HPV16/18 infected women who progress to highgrade cervical lesions or cancer [18, 19]. The present study was a real-world study and evaluated the prevalence of hrHPV genotypes and the correlation with HSIL+ risk, especially in hrHPV positive women with normal cytology.

The prevalence of hrHPV (12.1\%) obtained in the present study was lower than that reported in many Chinese cities [20]; however, it was slightly higher than that $(9.5 \%)$ reported in a previous study from the same region [21]. Moreover, previous population-based screening results have demonstrated that the overall prevalence of hrHPV varies from 9.9-27.5\% across China [22]. A previous study suggested possible reasons for this inconsistency, such as, different study populations, geographical prevalence, and differences in detection methods [23]. The HPV GenoArray test was a PCRbased kit that detected individual HPV genotypes. This technology has not been approved by the FDA, which could be a limitation of the study. Several studies have shown that the HPV GenoArray test is a reliable method for detecting and genotyping HPV infections [15, 24]. In accordance with previous data reported by Chinese population-based investigations [20-22], HPV16, HPV58 and HPV52 were found to be the dominant hrHPV types in the present study, followed by HPV53, HPV33 and HPV18. However, the results were distinctly different from those reported by a summarized global metaanalysis, in which HPV16 was the most frequently detected type; HPV18 ranked second place in CIN3 and ICC; HPV45 was more common than other nonHPV16/18 types in ICC [25]. In the present study, the most common genotypes in hrHPV positive women with normal cytology were mostly in accordance with those in all hrHPV positive women, with the exception that HPV18 was moved up to fifth place and HPV33 was moved down to sixth place.

The oncogenic potential varies with different hrHPV genotypes. A population-based study showed that HPV16, 58, 18, 52 and 33 were most common in persistent infection [26]. Another study showed that HPV16, 33 and 58 increased the risk of HSIL+ as compared with hrHPV-negative women [27]. Moreover, it has been shown -by Bayesian probability modeling - that there is the highest risk of HSIL+ in HPV16-positive patients; furthermore, HPV31- and HPV33/58-positive patients have a higher risk of HSIL+ compared to HPV18positive patients [28]. A European study showed that the most common HPV types in women with HSIL and cervical cancer were HPV16/33/31 (59.9/10.5/9.0\%) and 
HPV16/18/45 (63.3/15.2/5.3\%), respectively [29]. In a study from Denmark, HPV16, HPV18, HPV31 and HPV33 infection and especially HPV16 persistence were associated with high absolute risks for progression to high-grade cervical lesions [30]. In the present study, in women with normal cytology, HPV16 was the most common genotype in histological HSIL+; moreover, HPV52, 58, 33 and 31 were more common than HPV18. Moreover, the proportion of histological HSIL+ was not significantly different between women infected with HPV33 or HPV31 and women infected with HPV16. Although the prevalence of HPV53 was common, there was a low risk of developing HSIL+. In a study from Norway using a 5-type HPV mRNA test, after 6 years of follow-up, the cumulative proportions of highgrade cervical lesions were significantly higher in women who were HPV16 positive at baseline compared to women who were HPV31/33/45 positive at baseline. There were no differences, however, in high-grade cervical lesions between women who were HPV16 positive and women who were HPV18 positive at baseline [31]. Therefore, more studies are needed to confirm these results.

HPV genotyping will enable more precise characterization of cervical disease risk, but genotyping for only HPV16/18 is not sufficient. Although the prevalence and risk of HSIL+ in women with HPV18 didn't rank high among non-HPV16 types, HPV18 was one of the most common genotypes in adenoepithelial lesions. In the present study, HPV16/18 was positive in $63.2 \%$ of women with histological HSIL+. The addition of HPV31/33 genotyping to that of HPV16/18 could detect $14.3 \%$ more women with histological HSIL+. The OR for histological HSIL+ in women infected with HPV16/18/31/33 was higher than that in women infected with HPV16/18 (4.21 vs. 3.26). The addition of HPV31/33/52/58 genotyping to that of HPV16/18 could detect $93.1 \%$ of histological HSIL+ in the present study. The OR for histological HSIL+ was 5.73 in women infected with HPV16/18/31/33/52/58. A previous population-based, prospective, observational study suggested that HPV16/18/31/33/52/58 infection should be immediately referred for colposcopy [32]. However, in the present study, women infected with HPV16/18/31/33/52/ 58 accounted for $72.7 \%(1938 / 2665)$ of all hrHPV positive women with normal cytology; accordingly, the burden of colposcopy would increase. The results from our study support the need for immediate colposcopy in women infected with HPV16/18/31/33 in order to detect more HSIL+ cases; in addition, the colposcopy burden did not increase significantly. If colposcopy resource is sufficient, it is also recommended that women with HPV16/18/31/33/52/58 infection have immediate colposcopy.

\section{Conclusions}

In summary, wider hrHPV genotyping provides a better predictive value than HPV16/18 genotyping alone in guiding the clinical management of current cervical cancer screening. In northeastern China, the addition of HPV31/33 genotyping to that of HPV16/18 should be recommended in triaging women with a positive HPV test.

\section{Abbreviations}

HPV: Human papillomavirus; hrHPV: high-risk human papillomavirus; ACS: American Cancer Society; ASCCP: American Society for Colposcopy and Cervical Pathology; ASCP: American Society for Clinical Pathology; FDA: the American Food and Drug Administration; ICC: Invasive cervical cancer; CIN: Cervical intraepithelial neoplasia; HSIL: High-grade squamous intraepithelial lesion; PCR: Polymerase chain reaction; OR: Odds ratio; Cl: Confidence interval; FIGO: Federation International of Gynecology and Obstetrics; MA: Massachusetts; USA: United States of America

\section{Acknowledgements}

The authors would like to thank Mr. Te Qi for his excellent assistance in this work.

\section{Authors' contributions}

$J Z, D Y Z$ and DBW was responsible for conception, design and quality control of this study. JZ and DYZ conducted data curation, analyzed and interpreted the data, and were major contributor in writing the manuscript. ZY and XBW participated in investigation and statistical analysis. DBW reviewed and edited the manuscript. All authors read and approved the final manuscript.

\section{Funding}

This study was supported by National Key Research and Development Project "Research and Development of Digital Diagnostic and Medical Equipment" (grant number 20171FC0114204), Liaoning Province Key Research and Development Project (grant number 2018225037) and Liaoning Province Natural Science Foundation (grant number 20180550748). The funders had no role in study design, data collection and analysis, decision to publish, or preparation of the manuscript.

\section{Availability of data and materials}

The dataset analyzed in this study is available from the corresponding author upon reasonable request.

\section{Ethics approval and consent to participate}

The present study was approved by ethnics committee of Liaoning Cancer Hospital and Institute (20190971). Due to the retrospective nature without identifiable patient information, the requirement for informed consent was waived.

\section{Consent for publication}

Not applicable.

\section{Competing interests}

All authors declare there are no conflicts of interest.

\section{Author details}

'Department of Gynecology, Cancer Hospital of China Medical University, Liaoning Cancer Hospital and Institute, No.44 Xiaoheyan Road, Shenyang 110042, Liaoning province, China. ${ }^{2}$ Department of Obstetrics and Gynecology, Shengjing Hospital, China Medical University, No.36 Sanhao Street, Shenyang 110004, Liaoning province, China.

Received: 15 November 2019 Accepted: 6 May 2020

Published online: 19 May 2020

\section{References}

1. Torre LA, Bray F, Siegel RL, Ferlay J, Lortet-Tieulent J, Jemal A. Global cancer statistics, 2012. CA Cancer J Clin. 2015;65(2):87-108.

2. Munoz N, Bosch FX, de Sanjose S, Herrero R, Castellsague X, Shah KV, et al. Epidemiologic classification of human papillomavirus types associated with cervical cancer. N Engl J Med. 2003;348(6):518-27.

3. de Sanjose S, Quint WG, Alemany L, Geraets DT, Klaustermeier JE, Lloveras B, et al. Human papillomavirus genotype attribution in invasive cervical cancer: 
a retrospective cross- sectional worldwide study. Lancet Oncol. 2010;11(11): 1048-56.

4. Crosbie EJ, Einstein MH, Franceschi S, Kitchener HC. Human papillomavirus and cervical cancer. Lancet. 2013;382(9895):889-99.

5. Huh WK, Ault KA, Chelmow D, Davey DD, Goulart RA, Garcia FA, et al. Use of primary high-risk human papillomavirus testing for cervical cancer screening: interim clinical guidance. Gynecol Oncol. 2015;136(2):178-82.

6. Saslow D, Solomon D, Lawson HW, Killackey M, Kulasingam SL, Cain J, et al. American Cancer Society, American Society for Colposcopy and Cervical Pathology, and American Society for Clinical Pathology screening guidelines for the prevention and early detection of cervical cancer. Am J Clin Pathol. 2012;137(4):516-42.

7. Rijkaart DC, Berkhof J, van Kemenade FJ, Coupe VM, Hesselink AT, Rozendaal $L$, et al. Evaluation of 14 triage strategies for HPV DNA-positive women in population-based cervical screening. Int J Cancer. 2012;130(3):602-10.

8. Zhang Y, Wang Y, Liu L, Guo C, Liu Z, Nie S. Prevalence of human papillomavirus infection and genotyping for population-based cervical screening in developed regions in China. Oncotarget. 2016;7(38):62411-24.

9. Cuzick J, Ho L, Terry G, Kleeman M, Giddings M, Austin J, et al. Individual detection of 14 high risk human papilloma virus genotypes by the PapType test for the prediction of high grade cervical lesions. J Clin Virol. 2014;60(1): 44-9.

10. Thomsen LT, Frederiksen K, Munk C, Junge J, Iftner T, Kjaer SK. Long-term risk of cervical intraepithelial neoplasia grade 3 or worse according to highrisk human papillomavirus genotype and semiquantitative viral load among 33,288 women with normal cervical cytology. Int J Cancer. 2015;137(1):193203.

11. Li N, Franceschi S, Howell-Jones R, Snijders PJ, Clifford GM. Human papillomavirus type distribution in 30,848 invasive cervical cancers worldwide: variation by geographical region, histological type and year of publication. Int J Cancer. 2011;128(4):927-35.

12. Quek SC, Lim BK, Domingo E, Soon R, Park JS, Vu TN, et al. Human papillomavirus type distribution in invasive cervical cancer and high-grade cervical intraepithelial neoplasia across 5 countries in Asia. Int J Gynecol Cancer. 2013;23(1):148-56.

13. Bhatla N, Lal N, Bao YP, Ng T, Qiao YL. A meta-analysis of human papillomavirus type-distribution in women from South Asia: implications for vaccination. Vaccine. 2008:26:2811-7.

14. Xu QX, Zhang ZY. High-risk human papillomavirus genotypes in cervical lesions and vaccination challenges in China. Asian Pac J Cancer Prev. 2015; 16(6):2193-7.

15. Liu SS, Leung RCY, Chan KKL, Cheung ANY, Ngan HYS. Evaluation of a newly developed GenoArray human papillomavirus (HPV) genotyping assay and comparison with the Roche Linear Array HPV genotyping assay. J Clin Microbiol. 2010;48(3):758-64.

16. Stoler M, Bergeron C, Colgan TJ, Ferenczy A, Herrington AS, Kim K-R, et al. Squamous cell tumors and precursors. Tumors of the uterine cervix. In: Kurman RJ, Carcangiu ML, Herrington CS, Young RH, editors. WHO Classification of tumors of female reproductive organs. 4th ed. Lyon: IARC; 2014. p. 172-82.

17. Massad LS, Einstein MH, Huh WK, Katki HA, Kinney WK, Schiffman M, et al. Conference ACG. 2012 updated consensus guidelines for the management of abnormal cervical cancer screening tests and cancer precursors. J Low Genit Tract Dis. 2013;17(5 Suppl 1):S1-S27.

18. Khunamornpong S, Settakorn J, Sukpan K, Suprasert P, Srisomboon J, Intaraphet S, et al. Genotyping for human papillomavirus (HPV) 16/18/52/58 has a higher performance than HPV16/18 genotyping in triaging women with positive high-risk HPV test in northern Thailand. PLoS One. 2016;11(6): e0158184.

19. Gu L, Hong Z, Gao H, Qiu L, Di W. Incidence of cervical high-grade squamous intraepithelial lesions and squamous cell carcinoma in women with high-risk human papillomavirus and normal cervical cytology: a retrospective analysis of 1858 cases stratified by age and human papillomavirus genotype. Cytopathology. 2019;30(4):419-25.

20. Wang R, Guo XL, Wisman GB, Schuuring E, Wang WF, Zeng ZY, et al. Nationwide prevalence of human papillomavirus infection and viral genotype distribution in 37 cities in China. BMC Infect Dis. 2015;15:257.

21. Xue H, Lin X, Li T, Yan X, Guo K, Zhang Y. Prevalence and genotype distribution of human papillomavirus infection in asymptomatic women in Liaoning province, China. J Med Virol. 2015;87(7):1248-53.
22. Li J, Huang R, Schmidt JE, Qiao YL. Epidemiological features of human papillomavirus (HPV) infection among women living in mainland China. Asian Pac J Cancer Prev. 2013;14(7):4015-23.

23. Sun $P$, Song $Y$, Ruan $G$, Mao $X$, Kang $Y$, Dong $B$, et al. Clinical validation of the PCR-reverse dot blot human papillomavirus genotyping test in cervical lesions from Chinese women in the Fujian province: a hospital-based population study. J Gynecol Oncol. 2017;28(5):e50.

24. Liu X, Zhang S, Ruan Q, Ji Y, Ma L, Zhang Y. Prevalence and type distribution of human papillomavirus in women with cervical lesions in Liaoning Province, China. Int J Gynecol Cancer. 2010;20(1):147-53.

25. Guan P, Howell-Jones R, Li N, Bruni L, de Sanjosé S, Franceschi S, et al. Human papillomavirus types in 115,789 HPV-positive women: a metaanalysis from cervical infection to cancer. Int J Cancer. 2012;131(10):2349-59.

26. Wang S, Wei H, Wang N, Zhang S, Zhang Y, Ruan Q, et al. The prevalence and role of human papillomavirus genotypes in primary cervical screening in the northeast of China. BMC Cancer. 2012;12:160.

27. Wang $Y, X$ Ue J, Dai $X$, et al. Distribution and role of high-risk human papillomavirus genotypes in women with cervical intraepithelial neoplasia: a retrospective analysis from Wenzhou, Southeast China [published online ahead of print, 2018 may 30]. Cancer Med. 2018;7(7):3492-500.

28. Bonde J, Bottari F, Parvu V, Pedersen H, Yanson K, lacobone AD, et al. Bayesian analysis of baseline risk of CIN2 and $\geq$ CIN3 by HPV genotype in a European referral cohort. Int J Cancer. 2019;145(4):1033-41.

29. Tjalma WA, Fiander A, Reich O, Powell N, Nowakowski AM, Kirschner B, et al. Differences in human papillomavirus type distribution in high-grade cervical intraepithelial neoplasia and invasive cervical cancer in Europe. Int J Cancer. 2013;132(4):854-67.

30. Kjær SK, Frederiksen K, Munk C, Iftner T. Long-term absolute risk of cervical intraepithelial neoplasia grade 3 or worse following human papillomavirus infection: role of persistence. J Natl Cancer Inst. 2010;102(19):1478-88.

31. Sørbye SW, Fismen S, Gutteberg TJ, Mortensen ES, Skjeldestad FE. Primary cervical cancer screening with an HPV mRNA test: a prospective cohort study. BMJ Open. 2016;6(8):e011981.

32. Xu H, Lin A, Shao X, Shi W, Zhang Y, Yan W. Diagnostic accuracy of high-risk HPV genotyping in women with high-grade cervical lesions: evidence for improving the cervical cancer screening strategy in China. Oncotarget. 2016; 7(50):83775-83.

\section{Publisher's Note}

Springer Nature remains neutral with regard to jurisdictional claims in published maps and institutional affiliations.

Ready to submit your research? Choose BMC and benefit from:

- fast, convenient online submission

- thorough peer review by experienced researchers in your field

- rapid publication on acceptance

- support for research data, including large and complex data types

- gold Open Access which fosters wider collaboration and increased citations

- maximum visibility for your research: over $100 \mathrm{M}$ website views per year

At BMC, research is always in progress.

Learn more biomedcentral.com/submissions 